\title{
Role and mechanism of vascular cell adhesion molecule-1 in the development of rheumatoid arthritis
}

\author{
LAIFANG WANG, YANJIE DING, XIAQING GUO and QING ZHAO \\ Department of Rheumatology and Immunology, Huaihe Hospital of Henan University, \\ Kaifeng, Henan 475000, P.R. China
}

Received September 2, 2014; Accepted June 29, 2015

DOI: $10.3892 /$ etm.2015.2635

\begin{abstract}
The aim of the present study was to investigate the role and mechanism of vascular cell adhesion molecule-1 (VCAM-1) in the development of rheumatoid arthritis (RA). One hundred and twenty patients with RA who had been admitted to the Huaihe Hospital of Henan University between January and December 2013 were enrolled in the study as the observation group, while, in the corresponding period, 30 healthy volunteers were enrolled as the control group. The serum levels of VCAM-1 and rheumatoid factor (RF) were detected using ELISA. The patients underwent conventional treatment and their serum VCAM-1 and RF levels were detected at different time-points to determine their correlation. The observation group exhibited significantly higher serum VCAM-1 and RF levels than the control group $(\mathrm{P}<0.01)$. Twenty-four hours after treatment, the serum VCAM-1 levels of the patients peaked $(1,269.47 \pm 128.76 \mu \mathrm{g} / \mathrm{l}) ; 36 \mathrm{~h}$ after treatment, the serum RF levels peaked $(34.42 \pm 8.45 \mathrm{U} / \mathrm{ml}) ; 1$ month after treatment, the VCAM-1 and serum RF levels of the patients were lower than those prior to treatment $(\mathrm{P}<0.05)$. Pearson correlation analysis indicated that there was a significant, positive correlation between the serum VCAM-1 and RF levels in the patients with $\mathrm{RA}(\mathrm{r}=0.852, \mathrm{P}<0.01)$. In conclusion, the serum VCAM-1 levels of patients with RA increased and subsequently decreased as the condition was relieved, which could possibly be associated with the autoimmune and inflammatory reactions found in RA. Serum VCAM-1 levels can therefore reflect the disease condition and curative effects of treatment.
\end{abstract}

\section{Introduction}

Rheumatoid arthritis (RA) is a clinically common systemic autoimmune disease. In patients with RA, extensive

Correspondence to: Dr Qing Zhao, Department of Rheumatology and Immunology, Huaihe Hospital of Henan University, 115 Ximen Street, Kaifeng, Henan 475000, P.R. China

E-mail: qingzhaocn@163.com

Key words: vascular cell adhesion molecule-1, rheumatoid arthritis, mechanism irreversible bone and joint destruction appears in the first 2 years of the disease and later develops into ankylosis and deformity and leads to joint dysfunction, affecting the joint appearance and activity of the patients. Some patients become bed-bound, losing their ability to work and requiring care from others, which has serious consequences on their life and that of their family members (1-3). Early diagnosis of RA and timely treatment can effectively reduce bone and joint destruction, deformation and loss of function, and improve prognosis (4).

Rheumatoid factor (RF) is the only serological index used by the American Rheumatism Association for the diagnostic classification of RA and is currently used as an auxiliary in the diagnosis of RA (5). RF is a highly sensitive and accurate diagnostic marker for RA, but it has a low specificity; as a result, the diagnosis usually relies on other serological tests and symptom presentation (6). Vascular cell adhesion molecule-1 (VCAM-1) is generated by cells, can be found on the cell surface and mediates the contact and binding between cells or between the cells and stroma. As an adhesion molecule, VCAM-1 is involved in several vital physiological and pathological processes of the organism, including the viscosity of white blood cells and vascular cells during inflammatory processes, immune cell recognition, lymph node homing, tumor invasion and metastasis and intracellular signal transduction. VCAM-1 can interact with and influence interleukin (IL)-4, IL-8, tumor necrosis factor (TNF)- $\alpha$, TNF- $\beta$ and other inflammatory cytokines (7-9). Therefore, VCAM-1 affects, to some extent, inflammatory reactions, which may be associated with RA occurrence and development. Reports on the changes in VCAM-1 levels in RA and the association between the changes and the disease state are rare (10). In the present study, the changes in the serum VCAM-1 level and the effect of treatment on the VCAM-1 level were analyzed in patients with RA. In addition, Pearson correlation analysis was employed in order to analyze the correlation between the serum VCAM-1 and RF levels in patients with RA and provide a clinical basis for predicting the occurrence, development and outcome of RA.

\section{Subjects and methods}

Baseline characteristics. One hundred and twenty patients with RA who had been admitted to the Huaihe Hospital of 
Henan University (Kaifeng, China) between January and December 2013 were enrolled in the study as the observation group, and 30 healthy individuals in the corresponding period comprised the control group. The included patients were diagnosed with RA based on the RA classification and diagnostic criteria defined by the American Rheumatism Association in 1987 (11,12). The present study was conducted in accordance with the Declaration of Helsinki and was approved by the Ethics Committee of Huaihe Hospital of Henan University. Written informed consent was obtained from all participants. With regard to the severity of RA, 21 cases were classified as grade I, 44 cases as grade II, 52 cases as grade III and 3 cases as grade IV. The observation group consisted of 62 men and 58 women aged 28-85 years, with the mean age being $42.58 \pm 8.59$ years. The patients weighed $38-82 \mathrm{~kg}$ (mean, $57.24 \pm 9.85 \mathrm{~kg}$ ) and the mean arterial pressure was $85.98 \pm 7.24 \mathrm{mmHg}$. The control group comprised $15 \mathrm{men}$ and 15 women, aged 30-78 years (mean, $43.65 \pm 8.87$ years). The subjects weighed $40-81 \mathrm{~kg}$ (mean, $55.98 \pm 9.27 \mathrm{~kg}$ ), and the mean arterial pressure was $84.27 \pm 7.57 \mathrm{mmHg}$. No statistically significant differences were observed in the baseline characteristics between the two groups $(\mathrm{P}>0.05)$.

Treatment methods. According to the patients' conditions, nonsteroidal anti-inflammatory drugs, such as aspirin (Bayer AG, Leverkusen, Germany), were used for treatment. The patients also received anti-rheumatoid drugs, and certain patients with severe syndromes additionally underwent glucocorticoid treatment. The dose for symptom control was $35 \mathrm{mg} /$ day and the maintenance dose was $10 \mathrm{mg} /$ day. With regard to the patients with a limited joint movement range, obvious structural destruction and unbearable pain, corresponding joint replacement surgery or synovectomy was conducted. All patients received dietary guidance and support. When necessary, patients were given joint immobilization and prescribed bed-rest. The patients with mood disorders underwent psychological nursing intervention.

Detection methods. Fasting venous blood $(3 \mathrm{ml})$ was extracted from all patients 1 day after admission, and the blood samples were centrifuged at 4,000 x g for $5 \mathrm{~min}$ and then stored at $-20^{\circ} \mathrm{C}$ until use. Serum VCAM-1 and RF levels were detected using ELISA, and the kits were provided by Shanghai Ruiqi Biological Technology Co., Ltd. (Shanghai, China). The microplate reader was provided by Kunkeng Biological Technology Co., Ltd. (Shanghai, China). All experiments were performed according to the manufacturers' instructions. Following treatment, the indexes in the observation group were checked every $12 \mathrm{~h}$ from the start of treatment to 1 week after treatment and then rechecked once a week for 6 months.

Statistical analysis. All data were analyzed using SPSS 13.0 software (SPSS, Inc., Chicago, IL, USA). The $t$-test was used for the comparison between the two groups, while analysis of variance was used for the comparison among various measurement data. The q-test was used for further pairwise comparison, and the Pearson correlation coefficient was used for correlation analysis. $\mathrm{P}<0.05$ was considered to indicate a statistically significant difference.
Table I. Comparison of the pretreatment serum VCAM-1 and RF levels between the two groups.

\begin{tabular}{lccc}
\hline Groups & Cases & VCAM-1 $(\mu \mathrm{g} / \mathrm{l})$ & $\mathrm{RF}(\mathrm{U} / \mathrm{ml})$ \\
\hline Observation & 120 & $1125.58 \pm 125.89$ & $32.15 \pm 8.45$ \\
Control & 30 & $421.25 \pm 74.25$ & $13.26 \pm 4.17$ \\
$t$-test & & 12.47 & 8.95 \\
P-value & & $<0.01$ & $<0.01$ \\
\hline
\end{tabular}

VCAM-1, vascular cell adhesion molecule-1; RF, rheumatoid factor.

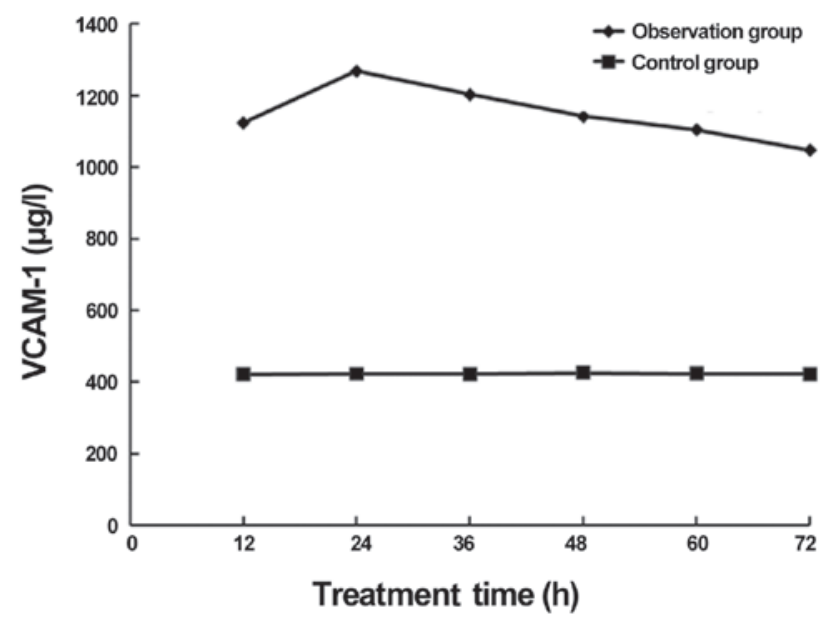

Figure 1. Serum VCAM-1 level changes following short-term treatment in the observation group. VCAM-1, vascular cell adhesion molecule-1.

\section{Results}

Comparison of serum VCAM-1 and RF levels between the two groups. Prior to treatment, the serum VCAM-1 and RF levels were significantly higher in the observation group than those in the control group $(\mathrm{P}<0.01)$ (Table I).

Comparison of serum VCAM-1 and RF levels at different treatment time-points in the observation group. The comparison of the serum VCAM-1 and RF levels at different treatment time-points in the observation group revealed statistically significant differences; compared with the levels of VCAM-1 and RF prior to treatment in the observation group $(\mathrm{P}<0.05)$, the levels 1, 3 and 6 months after treatment were significantly lower, and a gradual decrease was noted over the course of treatment $(\mathrm{P}<0.05)$. Twenty-four hours after treatment, the serum VCAM-1 levels of the patients peaked, while the serum RF levels peaked $36 \mathrm{~h}$ after treatment (Table II, Figs. 1-4).

Correlation between serum VCAM-1 and RF levels in patients with $R A$. The Pearson correlation analysis indicated that the increase in the serum VCAM-1 level occurred concurrently with an increase in the serum RF level in patients with RA, suggesting the presence of a significantly positive correlation between the two $(r=0.852, \mathrm{P}<0.01)$ (Fig. 5). 
Table II. Comparison of VCAM-1 and serum RF levels in the observation group at different treatment time-points.

\begin{tabular}{lcrr}
\hline Time-points & Cases & VCAM-1 $(\mu \mathrm{g} / 1)$ & $\mathrm{RF}(\mathrm{U} / \mathrm{ml})$ \\
\hline Before treatment & 120 & $1125.58 \pm 125.89$ & $32.15 \pm 8.45$ \\
1 week after treatment & 120 & $1096.58 \pm 105.69$ & $29.58 \pm 8.24$ \\
1 month after treatment & 120 & $982.57 \pm 98.65^{\mathrm{a}}$ & $25.55 \pm 9.14^{\mathrm{a}}$ \\
3 months after treatment & 120 & $741.52 \pm 79.48^{\mathrm{b}}$ & $22.15 \pm 9.22^{\mathrm{b}}$ \\
6 months after treatment & 120 & $581.47 \pm 65.72^{\mathrm{c}}$ & $20.28 \pm 7.62^{\mathrm{c}}$ \\
$t$-test & & 11.42 & 5.68 \\
P-value & & $<0.01$ & $<0.05$ \\
\hline
\end{tabular}

${ }^{\mathrm{a}} \mathrm{P}<0.05$, compared with before and 1 week after treatment; ${ }^{\mathrm{b}} \mathrm{P}<0.05$, compared with before, 1 week and 1 month after treatment; ${ }^{\mathrm{C}} \mathrm{P}<0.05$, compared with before, 1 week, 1 month and 3 months after treatment. VCAM-1, vascular cell adhesion molecule-1; RF, rheumatoid factor.

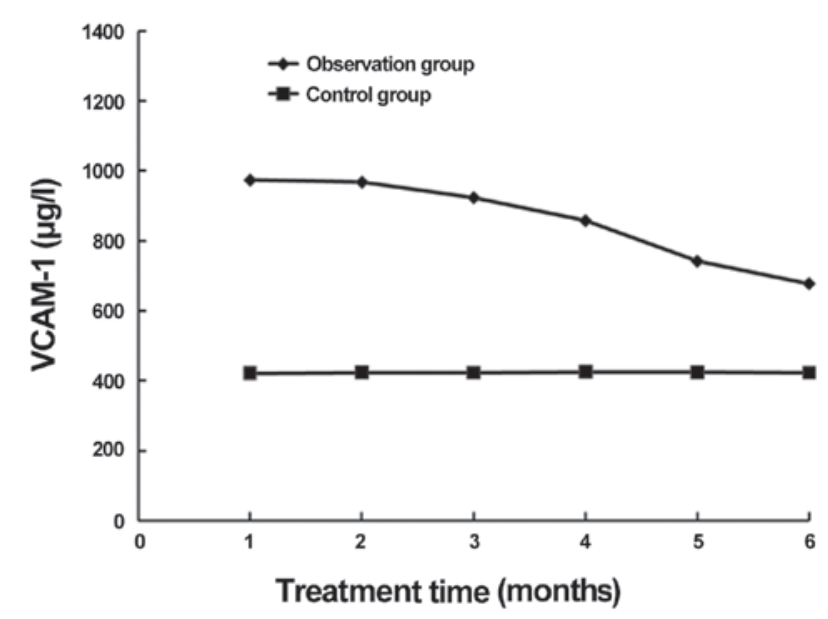

Figure 2. Serum VCAM-1 level changes following long-term treatment in the observation group. VCAM-1, vascular cell adhesion molecule-1.

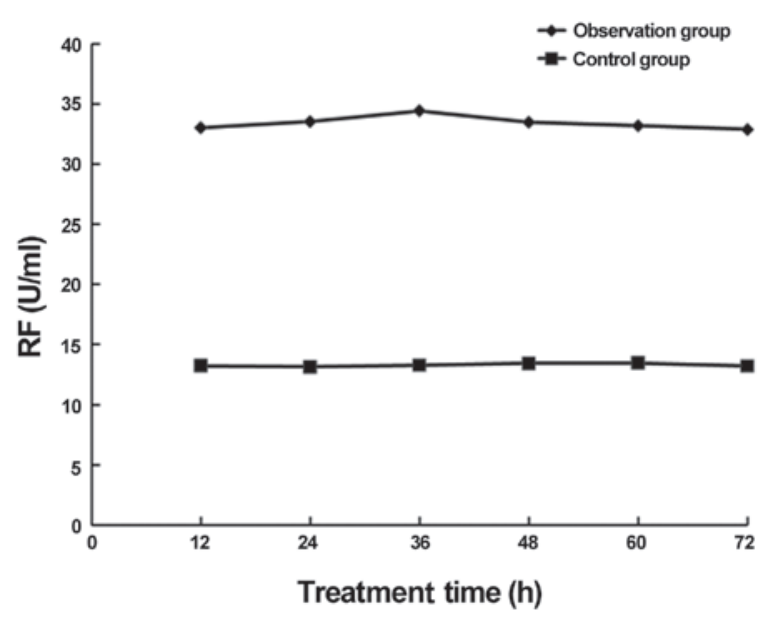

Figure 3. Serum RF level changes following short-term treatment in the observation group. RF, rheumatoid factor.

\section{Discussion}

RA is a chronic inflammatory disease that affects several symmetrical peripheral joints, leading to clinical manifestations of pain and swelling in the affected joints, pathological

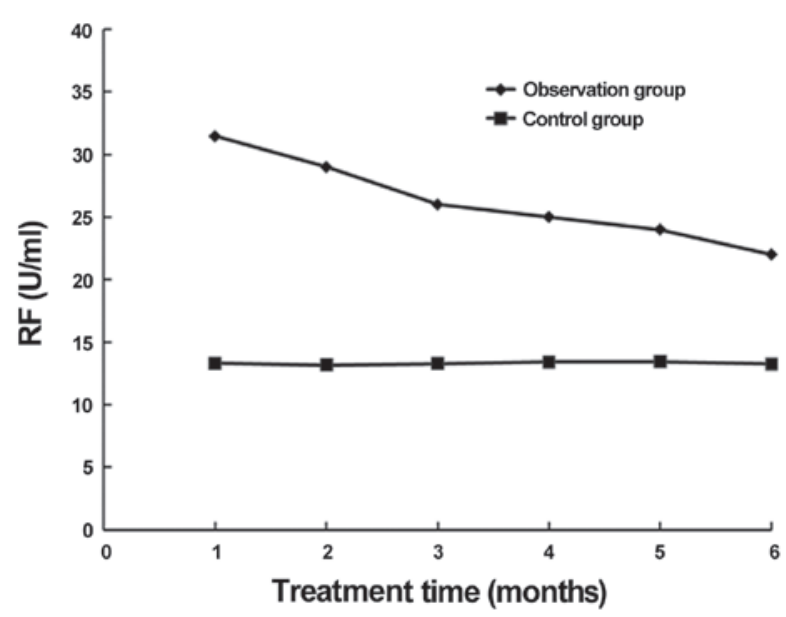

Figure 4. Serum RF level changes following long-term treatment in the observation group. RF, rheumatoid factor.

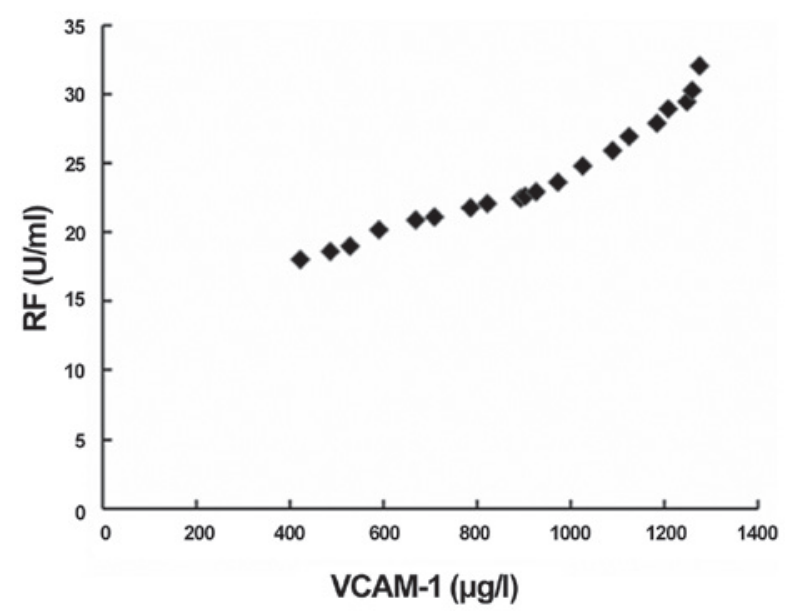

Figure 5. Correlation between serum VCAM-1 and RF levels in patients with rheumatoid arthritis. VCAM-1, vascular cell adhesion molecule-1; RF, rheumatoid factor.

changes and gradual dysfunction of the joints, as well as recurrent and unhealed symptoms $(13,14)$. The pathological changes are characteristic of erosive synovitis, which destroys the joint and affects several extra-articular systems. RA, therefore, 
has a strongly negative influence on the quality of life of the patients $(15,16)$. The cause of RA still remains unknown, as several factors can cause the autoimmune reactions of the organs, leading to pathological changes.

The principle pathogenic factors of RA are heredity and infections. Studies have shown that the descendants of patients with RA may have increased RF levels, even without exhibiting any RA symptoms, while infections caused by Mycoplasma and Streptococcus can also result in disorders of the autoimmune system, and thus induce RA $(17,18)$. The diagnosis of RA is made based on the clinical symptoms of the patients, X-ray results and RF detection results, and the serum RF level is the only serological indicator of RA $(19,20)$. VCAM-1 is an essential cell adhesion molecule and its expression can be induced by inflammatory cytokines, such as IL-6 and TNF, which participate in the differentiation and development of lymphocytes and are associated with the pathological processes of several diseases, including systemic inflammation, tumor invasion and metastasis, autoimmune diseases and parasitic infections $(21,22)$. As a chronic inflammatory disease, it is possible that RA is associated with VCAM-1; however, reports on the changes in the levels of VCAM-1 and its association with the development of RA are rare (10). Determining the function and mechanism of VCAM-1 in patients with RA could provide a strong clinical basis for the treatment of RA and the evaluation of the curative effects of the treatment.

The results of the present study showed that the serum VCAM-1 level was increased in the patients with RA, and that this increase continued for a short period of time during conventional treatment. With the prolongment of the treatment, certain clinical symptoms were relieved and the serum RF level decreased. The decline in the serum RF level was accompanied by a gradual decline in the serum VCAM-1 level, which suggests that the serum VCAM-1 level may be associated with the disease condition and serum RF level of the patients.

Pearson correlation analysis was employed in order to further study the correlation between the serum VCAM-1 and RF levels of the patients with RA. The results indicated that, in patients with RA, an increase in the serum VCAM-1 levels was accompanied by an increase in the serum RF levels, thus revealing a significantly positive correlation between the two. The serum VCAM-1 level can reflect the changes in the disease condition and, to some degree, the effect of the RA treatment. The present findings were consistent with the hypothesis that, as a chronic inflammatory disease, RA is associated with VCAM-1. The specific mechanism may be associated with the interaction of VCAM-1, IL and TNF, which adjusts levels of inflammatory cytokines and indirectly affects inflammatory reactions. High levels of VCAM-1 can markedly promote the release of inflammatory cytokines. VCAM-1 is involved in the formation of lymphocytes and the adjustment of the immune system, which also affects the immune system's function. High levels of serum VCAM-1 may be associated with the disorder of the immune system (23). RA is an autoimmune and inflammatory disease, so patients with RA may exhibit abnormal serum VCAM-1 levels. When the symptoms subside and the inflammatory reactions are reduced, the function of the immune system gradually returns to normal, and thus the serum VCAM-1 level progressively decreases.
The present study had certain limitations; the sample size was small and the observation time was short. Furthermore, the serum VCAM-1 levels in patients with RA are affected by several factors, and so a long-term study with a large sample size is required for the determination of the correlation between the VCAM-1 level in patients with RA and the curative effects of anti-RA treatment.

In conclusion, the serum VCAM-1 level in patients with RA first increases and then decreases, as the condition is relieved. The serum VCAM-1 levels of patients with RA may be associated with the autoimmune and inflammatory reactions of RA, and therefore reflect, to some extent, the disease condition and curative effects of treatment. The VCAM-1 levels could, consequently, assist the prediction of the effects of anti-RA treatment.

\section{References}

1. Paccou J, Boudot C, Renard C, Liabeuf S, Kamel S, Fardellone P, Massy Z, Brazier M and Mentaverri R: Total calcium-sensing receptor expression in circulating monocytes is increased in rheumatoid arthritis patients with severe coronary artery calcification. Arthritis Res Ther 16: 412, 2014.

2. Oiwa H, Mihara K, Kan T, Tanaka M, Shindo H, Kumagai K and Sugiyama E: Grade 3 lymphomatoid granulomatosis in a patient receiving methotrexate therapy for rheumatoid arthritis. Intern Med 53: 1873-1875, 2014.

3. Inoue M, Yanaihara N and Okamoto A: Salmonella ovarian abscess in a patient with rheumatoid arthritis (RA): A case report with literature review. Clin Exp Obstet Gynecol 41: 465-467, 2014.

4. Witkowski JM: Mechanisms of the immune system in ageing and some age-associated diseases. Postepy Biochem 60: 233-239, 2014 (In Polish).

5. Li G, Shi F, Liu J and Li Y: The effect of CTLA-4 A49G polymorphism on rheumatoid arthritis risk: A meta-analysis. Diagn Pathol 9: 157, 2014.

6. Sharma JN: Basic and clinical aspects of bradykinin receptor antagonists. Prog Drug Res 69: 1-14, 2014.

7. Yaman A, Karabag F, Demir S and Koken T: Changes in serum asymmetric dimethylarginine and endothelial markers levels with varying periods of hemodialysis. Ther Apher Dial 18: 361-367, 2014.

8. Mlinar LB, Chung EJ, Wonder EA and Tirrell M: Active targeting of early and mid-stage atherosclerotic plaques using self-assembled peptide amphiphile micelles. Biomaterials 35: 8678-8686, 2014.

9. Zheng Y, Yang W, Aldape K, He J and Lu Z: Epidermal growth factor (EGF)-enhanced vascular cell adhesion molecule-1 (VCAM-1) expression promotes macrophage and glioblastoma cell interaction and tumor cell invasion. J Biol Chem 288: 31488-31495, 2013.

10. Navarro-Hernández RE, Oregon-Romero E, Vázquez-Del Mercado M, Rangel-Villalobos H, Palafox-Sánchez CA and Muñoz-Valle JF: Expression of ICAM1 and VCAM1 serum levels in rheumatoid arthritis clinical activity. Association with genetic polymorphisms. Dis Markers 26: 119-126, 2009.

11. Alarcón GS, Blackburn WD Jr, Calvo A and Castañeda O: Evaluation of the American Rheumatism Association preliminary criteria for remission in rheumatoid arthritis: A prospective study. J Rheumatol 14: 93-96, 1987.

12. Ariza R, Van Walsem A, Canal C, Roldán C, Betegón L, Oyagüez I and Janssen K: Cost-minimization analysis of subcutaneous abatacept in the treatment of rheumatoid arthritis in Spain. Farm Hosp 38: 257-265, 2014 (In Spanish).

13. Kobelt G: Treating to target with etanercept in rheumatoid arthritis: Cost-effectiveness of dose reductions when remission is achieved. Value Health 17: 537-544, 2014.

14. Yokogawa N, Kaneko T, Nagai Y, Nunokawa T, Sawaki T, Shiroto K, Shimada K and Sugii S: Validation of RAPID3 using a Japanese version of Multidimensional Health Assessment Questionnaire with Japanese rheumatoid arthritis patients: Characteristics of RAPID3 compared to DAS28 and CDAI. Mod Rheumatol 25: 264-269, 2015.

15. Nazarinia M, Jalli R, Kamali Sarvestani E, Farahangiz S and Ataollahi M: Asymptomatic atlantoaxial subluxation in rheumatoid arthritis. Acta Med Iran 52: 462-466, 2014. 
16. Ponchel F, Burska AN and Vital EM: Pharmacogenomics in rheumatoid arthritis: How close are we to the clinic? Pharmacogenomics 15: 1275-1279, 2014.

17. Morgan MJ, Gamez G, Menke C, Hernandez A, Thorburn J, Gidan F, Staskiewicz L, Morgan S, Cummings C and Maycotte P: Regulation of autophagy and chloroquine sensitivity by oncogenic RAS in vitro is context-dependent. Autophagy 10: 1814-1826, 2014.

18. Cheng T, Wang M, Chen Z, Eisenberg RA, Zhang Y, Zou Y, Deng Y, Wang M and Zhou L: Tartrate-resistant acid phosphatase $5 \mathrm{~b}$ is a potential biomarker for rheumatoid arthritis: A pilot study in Han Chinese. Chin Med J (Engl) 127: 2894-2899, 2014.

19. Li S, Yu Y, Yue Y, Zhang Z and Su K: Microbial infection and rheumatoid arthritis. J Clin Cell Immunol 4: 174, 2013

20. Hafström I, Engvall IL, Rönnelid J, Boonen A, van der Heijde D and Svensson B; BARFOT study group: Rheumatoid factor and anti-CCP do not predict progressive joint damage in patients with early rheumatoid arthritis treated with prednisolone: A randomised study. BMJ Open 4: e005246, 2014.
21. Tan TW, Chou YE, Yang WH, Hsu CJ, Fong YC and Tang CH: Naringin suppress chondrosarcoma migration through inhibition vascular adhesion molecule-1 expression by modulating miR-126. Int Immunopharmacol 22: 107-114, 2014.

22. Mei H, Campbell JM, Paddock CM, Lertkiatmongkol P, Mosesson MW, Albrecht R and Newman PJ: Regulation of endothelial cell barrier function by antibody-driven affinity modulation of platelet endothelial cell adhesion molecule-1 (PECAM-1). J Biol Chem 289: 20836-20844, 2014.

23. Persidsky Y, Steffan AM, Gendrault JL, Royer C, Beyer C, Muchmore E, Kim A and Aubertin AM: Morphological changes in lymph nodes and expression of VCAM1 and cytokines at the late stages of SIV-induced disease in rhesus monkeys. Res Virol 146: 185-200, 1995. 